\title{
The impact of obesity on developmental coordination disorder in adolescence
}

\author{
Matthias Oliver Wagner ${ }^{\mathrm{a}, *}$, Julia Kastner $^{\mathrm{b}}$, Franz Petermann ${ }^{\mathrm{b}}$, Darko Jekauc ${ }^{\mathrm{c}}$, \\ Annette Worth ${ }^{\text {a }}$, Klaus Bös ${ }^{\mathrm{d}}$ \\ ${ }^{a}$ Institute for Health Science, Department of Sports and Movement, University of Education Schwäbisch Gmünd, Oberbettringer Str. 200, \\ 73525 Schwäbisch Gmünd, Germany \\ ${ }^{\mathrm{b}}$ Centre for Clinical Psychology and Rehabilitation, University of Bremen, 28359 Bremen, Germany \\ ${ }^{\mathrm{c}}$ University of Konstanz, 78457 Konstanz, Germany \\ ${ }^{\mathrm{d}}$ Institute for Sports and Sports Science, Karlsruhe Institute of Technology, 76131 Karlsruhe, Germany
}

Keywords:

Developmental coordination disorder Obesity

Adolescence

\begin{abstract}
A B S T R A C T
Developmental coordination disorder (DCD) as well as overweight and obesity are of increasing importance in the study of human development. Data on the relation between DCD and obesity in adolescence are of particular interest because both phenomena are unlikely to disappear with age. The objective of this study was to determine the impact of obesity on severe DCD in adolescence. A total of 99 obese adolescents aged between 11 and 16 years and 99 normal weight controls matched for age and gender were included in this cross sectional study. The Movement Assessment Battery for Children 2 (age band 3) was used to determine subjects' stage of motor development. Results made clear that (i) obese show a higher severe DCD risk in comparison to normal weight adolescents $(p<.01)$ which is (ii) most pronounced in balance $(p<.01)$, and (iii) thereby rather appears in boys $(p \leq .10)$. Thus, our results at least do not exclude the possibility that obesity might have a detrimental effect on the etiopathology of DCD beyond childhood. Therefore, primary obesity prevention measures may additionally contribute to the prevention of a possible consolidation of severe DCD.
\end{abstract}

\section{Introduction}

\subsection{Relevance, concepts and key assumptions}

Developmental coordination disorder (DCD) as well as overweight and obesity are of increasing importance in the study of human development mainly because both conditions are associated with a number of comorbidities (Schelbert, 2009; Visser, 2003) and rising prevalence rates that differ between cultures (Tsiotra et al., 2006; [WHO], 2007).

Following the diagnostic criteria provided in the Diagnostic and Statistic Manual of Mental Disorders (DSM IV TR; American Psychiatric Association [APA], 2000) DCD is most likely present when "Performance in daily activities that require motor co ordination is substantially below that expected given the person's chronological age and measured intelligence" (APA, 2000). Furthermore, it is important to note that "The disturbance is not due to a general medical condition [...] and

\footnotetext{
* Corresponding author. Tel.: +49 7171983 320; fax: +49 7171983371.

E-mail address: matthias.wagner@ph-gmuend.de (M.O. Wagner).
} 
does not meet criteria for a pervasive developmental disorder" (APA, 2000). Overweight and obesity are defined as abnormal or excessive fat accumulation that may impair health (WHO, 2011).

When discussing the relation between DCD and overweight/obesity two key assumptions should be considered. On one hand, it has been suggested that DCD or low motor proficiency, respectively, could lead to a lack of physical activity (PA; Bouffard, Watkinson, Thompson, Causgrove Dunn, \& Romanow, 1996; Wrotniak, Epstein, Dorn, Jones, \& Kondilis, 2006; for the mediating role of generalized self efficacy regarding PA see Cairney et al., 2005) which may increase the risk for being overweight or obese (key assumption a; for the mediating role of PA in the relation between DCD and body fat see Faught, Hay, Cairney, \& Flouris, 2005).

However, if we consider DCD as well as overweight and obesity as parts of a dynamic and reciprocally structured system (Hands \& Larkin, 2002) it is also feasible, that overweight and obesity could lead to a lack of PA (for PA differences between normal weight and overweight see Deforche, De Bourdeaudhuij, D'Hondt, \& Cardon, 2009a) which may negatively influence the etiopathology of DCD beyond childhood (key assumption $b$ ).

\subsection{Empirical evidence and research desiderata}

The relation of DCD and body composition has received much attention in the literature (see the review by Rivilis et al., 2011). While two out of three recently published longitudinal studies (Cairney et al., 2010; Osika \& Montgomery, 2008; in contrast Hands, 2008) provide some empirical evidence supporting key assumption (a), longitudinal data supporting key assumption (b) are lacking. Results of recent cross sectional studies at least indicate that:

(i) the general motor skill level in obese is lower than that in normal weight and overweight children (e.g. Zhu, Wu, \& Cairney, 2011),

(ii) these differences are particularly pronounced for (static and dynamic) balance (BL; D'Hondt, Deforche, De Bourdeaudhuij, \& Lenoir, 2009; Zhu et al., 2011; in depth Graf et al., 2004), followed by ball skills (here: aiming and catching, AC; D'Hondt et al., 2009; in contrast Zhu et al., 2011) and finally fine motor skills (here: manual dexterity, MD; D'Hondt et al., 2009; in contrast Zhu et al., 2011; in depth under different postural constraints D'Hondt, Deforche, De Bourdeaudhuij, \& Lenoir, 2008), and

(iii) these differences in balance are more pronounced in boys than in girls (Mond, Stich, Hay, Kraemer, \& Baune, 2007; partially Cawley \& Spiess, 2008; in contrast Zhu et al., 2011; in depth for boys Deforche et al., 2009b; Goulding, Jones, Taylor, Piggot, \& Taylor, 2003).

However, besides the lack of longitudinal evidence, current research on key assumption (b) appears fragmentary as most of the studies citied under (i) (iii) refer to childhood whereas data in adolescence are lacking to a large extend. However, these data would be particularly relevant because children with a (severe) DCD diagnosis are unlikely to outgrow these deficits during adolescence (e.g. Cantell, Smyth, \& Ahonen, 2003) and the increasing prevalence of childhood overweight and obesity presumably persists as children grow older (WHO, 2007).

\subsection{Study aim, research question and hypotheses}

The aim of this study was to determine the impact of overweight/obesity on DCD in adolescence. From a clinical perspective and in accordance with the current literature (Cantell et al., 2003), we particularly focused on the distinction between typically developing adolescents (TD) and those with a severe DCD (SDCD) diagnosis in order to facilitate identifying risk groups with proven needs. In statistical terms (maximization of primary variance; Kerlinger \& Lee, 2000) the distinction between normal weight and obese adolescents promised the highest explanatory power. Therefore, we specifically questioned the impact of obesity on SDCD in adolescence and hypothesized that:

(i) There is an impact of obesity on SDCD in adolescence because we expect obese to show a higher SDCD risk in comparison to normal weight adolescents.

(ii) The level of impact of obesity on SDCD in adolescence is task specific because we expect the higher SDCD risk of obese in comparison to normal weight adolescents to be most pronounced in balance (BL) followed by aiming and catching (AC) and finally manual dexterity (MD).

(iii) The level of impact of obesity on BL SDCD in adolescence is gender specific because we expect the higher BL SDCD risk of obese in comparison to normal weight adolescents to be more pronounced in boys than in girls.

\section{Materials and methods}

\subsection{Sample and clinical obesity criteria}

A total of 99 obese adolescents (Diagnosis by ICD 10 E66; 66.8; 66.9, WHO, 1993; BMI >97th percentile, Kromeyer Hauschild et al., 2010) in clinical treatment (Clinical Intervention Group, CIG: mean age =14.04, SD=1.29 [11;00 16;00]; 
Table 1

Anthropometric characteristics of the CIG. ${ }^{a}$

\begin{tabular}{|c|c|c|c|c|}
\hline Measurement & & Total & Boys & Girls \\
\hline \multirow[t]{5}{*}{$\mathrm{BMI}^{\mathrm{b}}\left[\mathrm{kg} / \mathrm{m}^{2}\right]$} & Mean & 33.33 & 33.56 & 33.09 \\
\hline & $S D$ & 3.71 & 3.84 & 3.60 \\
\hline & Min & 25.15 & 25.93 & 25.15 \\
\hline & Max & 41.87 & 41.87 & 40.46 \\
\hline & $N$ & 78 & 40 & 38 \\
\hline \multirow[t]{5}{*}{ Height [m] } & Mean & 1.66 & 1.68 & 1.64 \\
\hline & $S D$ & 0.08 & 0.09 & 0.05 \\
\hline & Min & 1.50 & 1.50 & 1.53 \\
\hline & Max & 1.83 & 1.83 & 1.75 \\
\hline & $N$ & 79 & 41 & 38 \\
\hline \multirow[t]{5}{*}{ Mass [kg] } & Mean & 92.13 & 94.83 & 89.28 \\
\hline & $S D$ & 13.47 & 15.31 & 10.68 \\
\hline & Min & 62.00 & 67.00 & 62.00 \\
\hline & Max & 129.00 & 129.00 & 105.00 \\
\hline & $N$ & 80 & 41 & 39 \\
\hline
\end{tabular}

Clinical intervention group.

b Body mass index.

boys: $N=52$, mean age $=13.79, S D=1.33$ [11.00 16.00]; girls: $N=47$, mean age $=14.32, S D=1.20$ [11.00 16.00]) and 99 normal weight control subjects (Control Group, CG) matched for age and gender ${ }^{1}$ were originally included in this cross sectional study. At the time of data collection, 17 CIG subjects fell below the 97th BMI percentile and were therefore excluded from further considerations. Table 1 shows the final anthropometric characteristics of the CIG.

\subsection{DCD Diagnosis}

The Movement Assessment Battery for Children 2 (age band 3; Henderson, Sugden, \& Barnett, 2007) respectively its German language adaptation (Petermann, 2009) was used to determine the stage of motor development in both groups. Measurements for eight subtests assigned to the three dimensions manual dexterity (MD), aiming and catching (AC) and balance (BL) were recorded and summed to a total impairment score (TIS). Participants were classified as TD (PR $>15$ ), border line DCD (PR 6 15) or SDCD (PR $\leq 5)$.

\subsection{Data analysis}

After elimination of borderline cases and pairwise deletion of missing data, ${ }^{2}$ a minimum of 156 complete data sets remained (TIS: $N=156$, CIG: $N=64$, CG $N=92 ;$ MD: $N=165$, CIG: $N=71$, CG: $N=94 ;$ AC: $N=170$, CIG: $N=77$, CG: $N=93$; BL: $N=165$, CIG: $N=71$, CG: $N=94)$.

Logistic regression was used to test the directional hypotheses (one sided testing). Weight status (normal weight as reference category, obesity) was used to predict the change in DCD risk from TD to SDCD. Because of the large age range, chronological age was included as a control variable in all statistical tests. In addition, the assumption of gender specific influences (hypothesis iii) necessitated the inclusion of gender in the tests addressing hypothesis (i) and (ii). Gender specific influences of obesity on BL SDCD were tested by considering the dummy coded group $\times$ gender interaction. The significance level for all statistical tests was set a priori to $\alpha=.050$. All statistical tests were carried out in SPSS 19 (IBM, New York, USA).

\section{Results}

\subsection{Descriptive measures}

Descriptive measures (see Table 2) showed (i) a higher prevalence of obese (CIG; 28.1\%) with TIS SDCD in comparison to their normal weight controls (CG; 3.3\%), (ii) a comparatively high prevalence of MD SDCD (26.8\%) in obese, which can be explained by a disproportionately low prevalence of obese boys with AC SDCD (11.9\%) and (iii) a disproportionately low prevalence of obese girls with BL SDCD (21.2\%).

\subsection{Hypothesis testing}

Logistic regressions (Tables 3 7) showed that (i) controlled for age and gender, obese participants had a 11.74 higher SDCD risk in comparison to normal weight adolescents (Table 3), (ii) controlled for age and gender, the higher SDCD risk for

\footnotetext{
${ }^{1}$ Matching method was chosen because an active manipulation of weight-status was not possible.

2 Pairwise deletion was considered appropriate because the proportion of missing item responses for each scale only ranged from 0.6 to $5.5 \%$ and the overall percentage of missing data was $1.93 \%$ (21 out of 1.186 ).
} 
Table 2

Prevalence of SDCD among obese and normal-weight boys and girls.

\begin{tabular}{|c|c|c|c|c|c|c|}
\hline & \multicolumn{2}{|l|}{ Total } & \multicolumn{2}{|l|}{ Boys } & \multicolumn{2}{|l|}{ Girls } \\
\hline & $\mathrm{CG}^{\mathrm{a}}$ & $\mathrm{CIG}^{\mathrm{b}}$ & $\mathrm{CG}^{\mathrm{a}}$ & $\mathrm{CIG}^{\mathrm{b}}$ & $\mathrm{CG}^{\mathrm{a}}$ & $\mathrm{CIG}^{\mathrm{b}}$ \\
\hline & $\%(N)$ & $\%(N)$ & $\%(N)$ & $\%(N)$ & $\%(N)$ & $\%(N)$ \\
\hline TIS $^{\mathrm{c}}$ & $3.3(92)$ & $28.1(64)$ & $2.0(51)$ & $25.7(35)$ & $4.9(41)$ & $31.0(29)$ \\
\hline $\mathrm{MD}^{\mathrm{d}}$ & $7.4(94)$ & $26.8(71)$ & $8.5(47)$ & $25.6(39)$ & $6.4(47)$ & 28.1 \\
\hline$A C^{e}$ & $6.5(93)$ & $19.5(77)$ & $3.8(52)$ & $11.9(42)$ & $9.8(41)$ & $28.6(35)$ \\
\hline $\mathrm{BL}^{\mathrm{f}}$ & $5.3(94)$ & $26.8(71)$ & $2.0(49)$ & $31.6(38)$ & $8.9(45)$ & $21.2(33)$ \\
\hline
\end{tabular}

${ }^{\mathrm{a}}$ Control group (normal-weight).

b Clinical intervention group (obese).

c Total impairment score.

d Manual dexterity.

e Aiming and catching.

f Balance.

Table 3

Logistic regression to determine the impact of obesity on TIS-SDCDa $(N=156)$.

\begin{tabular}{|c|c|c|c|c|c|}
\hline Predictor & B & Wald-Chi $^{2}$ & df & $p^{\mathrm{b}}$ & OR \\
\hline Group $\left(\mathrm{CIG}^{\mathrm{C}}\right)$ & 2.46 & 14.30 & 1 & .000 & 11.74 \\
\hline Age & -0.05 & 0.05 & 1 & .416 & 0.96 \\
\hline Gender (girls) & 0.41 & 0.62 & 1 & .216 & 1.51 \\
\hline Intercept & -2.97 & 1.00 & 1 & .158 & 0.05 \\
\hline
\end{tabular}

-2 Log-likelihood = 101.87; Nagelkerkes $R^{2}=.235$.

a Total impairment score - severe developmental coordination disorder.

b $p$-Value (one-sided testing).

c Clinical intervention group.

Table 4

Logistic regression to determine the impact of obesity on MD-SDCD ${ }^{\mathrm{a}}(N=165)$.

\begin{tabular}{|c|c|c|c|c|c|}
\hline Predictor & $B$ & Wald-Chi ${ }^{2}$ & $\mathrm{df}$ & $p^{\mathrm{b}}$ & OR \\
\hline Group $\left(\mathrm{CIG}^{\mathrm{C}}\right)$ & 1.51 & 10.00 & 1 & .001 & 4.51 \\
\hline Age & 0.08 & 0.18 & 1 & .337 & 1.08 \\
\hline Gender (girls) & -0.07 & 0.02 & 1 & .443 & 0.94 \\
\hline Intercept & -3.60 & 1.87 & 1 & .086 & 0.03 \\
\hline
\end{tabular}

-2 Log-likelihood $=132.13 ;$ Nagelkerkes $R^{2}=.117$.

a Manual dexterity - severe developmental coordination disorder.

b $p$-Value (one-sided testing).

c Clinical intervention group.

Table 5

Logistic regression to determine the impact of obesity on AC-SDCD $(N=170)$.

\begin{tabular}{lrlll}
\hline Predictor & \multicolumn{1}{l}{ B } & Wald-Chi ${ }^{2}$ & df & $p^{\mathrm{b}}$ \\
\hline Group $\left(\mathrm{CIG}^{\mathrm{C}}\right.$ ) & 1.28 & 6.07 & 1 & .007 \\
Age & -0.06 & 0.09 & 1 & .380 \\
Gender (girls) & 1.10 & 4.40 & 1 & .018 \\
Intercept & -2.40 & 0.70 & 1 & .94 \\
\hline
\end{tabular}

-2 Log-likelihood = 115.63; Nagelkerkes $R^{2}=.124$

a Aiming and catching - severe developmental coordination disorder.

b $p$-Value (one-sided testing).

c Clinical intervention group.

Table 6

Logistic regression to determine the impact of obesity on BL-SDCD $(N=165)$.

\begin{tabular}{lrrrr}
\hline Predictor & \multicolumn{1}{l}{ B } & Wald-Chi ${ }^{2}$ & df & $p^{\text {b }}$ \\
\hline Group $\left(\mathrm{CIG}^{\mathrm{c}}\right.$ ) & 1.87 & 12.34 & 1 & .000 \\
Age & 0.08 & 0.18 & 1 & .334 \\
Gender (girls) & -0.10 & 0.04 & 1 & .49 \\
Intercept & -3.96 & 2.25 & 1 & .08 \\
\hline
\end{tabular}

-2 Log-likelihood = 121.36; Nagelkerkes $R^{2}=.159$.

a Balance - severe developmental coordination disorder.

b $p$-Value (one-sided testing).

c Clinical intervention group. 
Table 7

Logistic regression to determine the gender-specific impact of obesity on BL-SDCD ${ }^{\mathrm{a}}(N=165)$.

\begin{tabular}{lrlrr}
\hline Predictor & \multicolumn{1}{l}{ B } & Wald-Chi ${ }^{2}$ & df & $p^{\text {b }}$ \\
\hline Group $\left(\mathrm{CIG}^{\mathrm{c}}\right)$ & 3.10 & 8.38 & 1 & .002 \\
Age & 0.08 & 0.17 & 1 & .340 \\
Gender (girls) & 1.50 & 1.71 & 1 & .096 \\
Group $\times$ gender & -2.08 & 2.71 & 1 & .08 \\
Intercept & -4.95 & 3.10 & 1 & .050 \\
\hline
\end{tabular}

-2 Log-likelihood = 118.09; Nagelkerkes $R^{2}=.191$.

a Balance - severe developmental coordination disorder.

b $p$-Value (one-sided testing).

c Clinical intervention group.

obese subjects in comparison to normal weight adolescents was most pronounced in balance (BL: OR=6.49; Table 6) followed by manual dexterity (MD: $\mathrm{OR}=4.51$; Table 4) and aiming and catching ( $\mathrm{AC}$ : $\mathrm{OR}=3.58$; Table 5), and (iii) controlled for age and at least in tendency, the higher BL SDCD risk of obese was slightly more pronounced in boys (group $\times$ gender interaction: $p=.050$; Table 7).

\section{Discussion}

\subsection{Progress of knowledge, summary and explanations}

This study provides novel data because it is one among few studies explicitly focusing on the impact of obesity on severe DCD in adolescence.

The results of this study indicate that (i) there is an impact of obesity on TIS SDCD in adolescence because obese subjects showed a higher TIS SDCD risk in comparison to their normal weight controls, (ii) the level of impact (of obesity on SDCD in adolescence) is task specific because the higher BL SDCD risk of obese in comparison to their normal weight controls was most pronounced in balance followed by manual dexterity and aiming and catching, and (iii) the impact of obesity on BL SDCD may depend on gender because the higher SDCD risk of obese in comparison to their normal weight controls was slightly more pronounced in boys.

Since (task and gender specific) significant differences in the prevalence of SDCD between normal weight and obese are still identifiable in adolescence, our results at least do not exclude the possibility that obesity might have a detrimental effect on the etiopathology of SDCD beyond childhood (key assumption b). Therefore, the results of this study may be explained as follows. Hypothesis (i): Obese are generally assumed to have a unique set of physiological, biomechanical, and neuromuscular barriers to PA and thus are more susceptible to a more sedentary lifestyle in comparison to their normal weight peers (Shultz, Deforche, Byrne, \& Hills, 2011). Resulting reduced opportunities to experience and challenge their own body could therefore make obese more susceptible to consolidate an already existing SDCD in comparison to their normal weight SDCD peers. Hypothesis (ii): An active lifestyle is usually accompanied by a variety of different locomotive activities such as running, jumping, and climbing, and one of the main prerequisite for these activities is healthy postural control (Haywood \& Getchell, 2005). An obesity induced shift towards a less active lifestyle presumably leads to a lack of locomotion and therefore to a lack of situations that train and challenge postural control. This pathway represents one possibly explanation for the comparatively high BL SDCD risk in obese. However, aiming and catching tasks also rely on postural balance control, and hence we would have expected a larger impact in comparison to MD SDCD in this regard.

Hypothesis (iii): The higher BL SDCD risk in obese boys may simply reflect the observation that girls are generally more skilled in static and dynamic balance tasks (Mickle et al., 2011; Wagner, Worth, Schlenker, \& Bös, 2010).

\subsection{Implications, limitations and recommendations/challenges}

If the explanations provided above hold true, task and gender specific intervention strategies (in overview Polatajko \& Cantin, 2005) should be combined with primary obesity prevention measures (in overview Connelly, Duaso, \& Butler, 2007) at an early stage to prevent a possible consolidation of SDCD beyond childhood.

However, our considerations are based on cross sectional data that do not provide final empirical evidence on the causal relationship. In addition, the current study did not include any measurement of PA, and hence the assumption of a mediated impact remains hypothetical. Besides the unanswered questions of directionality and mediation one may question the use of M ABC 2 as it has not been established as the gold standard in diagnosing DCD, yet (Venetsanou et al., 2011). However, recent work at least proves factorial validity of $M A B C 2$ for age band 1 (Ellinoudis et al., 2011) and 2 (Wagner, Kastner, Petermann, \& Bös, 2011) as well as its clinical relevance (Kastner, Mayer, Walther, \& Petermann, 2010; Kastner, Petermann, \& Petermann, 2010). Finally, BMI may not be a sufficiently sensitive measure for determining obesity (Rivilis et al., 2011; in contrast Willett, Jiang, Lenart, Spiegelman, \& Willett, 2006). 
Therefore, future investigations should implement extreme group comparisons into longitudinal designs including the concept of PA with a simultaneous use of additional DCD (Brown \& Lalor, 2009) and alternative body composition (Rivilis et al., 2011) measurements.

\section{Conclusion}

Our results suggest that obesity could be detrimental for a (task and gender specific) consolidation of severe DCD beyond childhood because corresponding differences between normal weight and obese subjects are still present in adolescence. However, because of the cross sectional design of this study and the limited validity of measurements, final empirical evidence is still lacking.

\section{Conflict of interest statement}

The authors declare that there is no actual or potential conflict of interest.

\section{Acknowledgements}

The authors would like to thank Priv. Doz. Dr. Annegret Mündermann (ABR Solutions) who provided scientific writing services on behalf of the authors. Furthermore, the authors would like to thank Prof. Dr. Hans Christian Waldmann (University of Bremen) for productive and collegial discussions.

\section{References}

American Psychiatric Association. (2000). Diagnostic and Statistical Manual of Mental Disorders (4th ed.). Text Revision. Washington, DC: Authors. Bouffard, M., Watkinson, E. J., Thompson, L. P., Causgrove Dunn, J., \& Romanow, S. K. E. (1996). A test of the activity deficit hypothesis with children with movement difficulties. Adapted Physical Activity Quarterly, 13, 61-73.

Brown, T., \& Lalor, A. (2009). The Movement Assessment Battery for Children - Second Edition (MABC-2): A review and critique. Physical \&' Occupational Therapy in Pediatrics, 29, 86-103.

Cairney, J., Hay, J. A., Faught, B. E., Wade, T. J., Corna, L. M., \& Flouris, A. (2005). Developmental coordination disorder, generalized self-efficacy toward physical activity, and participation in organized and free play activities. The Journal of Pediatrics, 147, 515-520.

Cairney, J., Hay, J., Veldhuizen, S., Missiuna, C., Mahlberg, N., \& Faught, B. E. (2010). Trajectories of relative weight and waist circumference among children with and without developmental coordination disorder. Canadian Medical Association Journal, 182, 1167-1172.

Cantell, M. H., Smyth, M. M., \& Ahonen, T. P. (2003). Two distinct pathways for developmental coordination disorder: Persistence and resolution. Human Movement Science, 22, 413-431.

Cawley, J., \& Spiess, C. K. (2008). Obesity and skill attainment in early childhood. Economics and Human Biology, 6, 388-397.

Connelly, J. B., Duaso, M. J., \& Butler, G. (2007). A systematic review of controlled trials of interventions to prevent childhood obesity and overweight: A realistic synthesis of the evidence. Public Health 121, 510-517.

Deforche, B., De Bourdeaudhuij, I., D’Hondt, E., \& Cardon, G. (2009a). Objectively measured physical activity, physical activity related personality and body mass index in 6-to10-yr-old children: A cross-sectional study. International Journal of Behavioral Nutritional and Physical Activity, 6, 25.

Deforche, B. I., Hills, A. P., Worringham, C. J., Davies, P. S. W., Murphy, A. J., Bouckaert, J. J., et al. (2009b). Balance and postural skills in normal-weight and overweight prepubertal boys. International Journal of Pediatric Obesity, 4, 175-182.

D’Hondt, E., Deforche, B., De Bourdeaudhuij, I., \& Lenoir, M. (2008). Childhood obesity affects fine motor skill performance under different postural constraints. Neuroscience Letters, 440, 72-75.

D’Hondt, E., Deforche, B., De Bourdeaudhuij, I., \& Lenoir, M. (2009). Relationship between motor skill and body mass index in 5- to 10-year old children. Adapted Physical Activity Quarterly, 26, 21-37.

Ellinoudis, T., Evaggelinou, C., Kourtessis, T., Konstantinidou, Z., Venetsanou, F., \& Kambas, A. (2011). Reliability and validity of age band 1 of the Movement Assessment Battery for Children - Second Edition. Research in Developmental Disabilities, 32, 1046-1051.

Faught, B. E., Hay, J. A., Cairney, J., \& Flouris, A. (2005). Increased risk for coronary vascular disease in children with developmental coordination disorder. Journal of Adolescent Health, 37, 376-380.

Goulding, A., Jones, I. E., Taylor, R. W., Piggot, J. M., \& Taylor, D. (2003). Dynamic and static tests of balance and postural sway in boys: Effects of previous wrist bone fractures and high adiposity. Gait \&' Posture, 17, 136-141.

Graf, C., Koch, B., Kretschmann-Kandel, E., Falkowski, G., Christ, H., Coburger, S., et al. (2004). Correlation between BMI, leisure habits and motor abilities in childhood (CHILT-project). International Journal of Obesity, 28, 22-26.

Hands, B. (2008). Changes in motor skill and fitness measures among children with high and low motor competence: A five-year longitudinal study. Journal of Science and Medicine in Sport, 11, 155-162.

Hands, B., \& Larkin, D. (2002). Physical fitness and developmental coordination disorder. In S. A. Cermak \& D. Larkin (Eds.), Developmental coordination disorder (pp. 172-184). Albany, NY: Delmar.

Haywood, K. M., \& Getchell, N. (2005). Life Span Motor Development (5th ed.). Champaign, IL: Human Kinetics.

Henderson, S. G., Sugden, D. A., \& Barnett, A. L. (2007). Movement Assessment Battery for Children-2. London: Pearson Assessment.

Kastner, J., Mayer, H., Walther, A., \& Petermann, F. (2010). Motorisch-koordinative Leistungsfähigkeit adipöser Jugendlicher. Zur klinischen Aussagekraft der Movement ABC-2 [Movement abilities of obese adolescents: Clinical validity of the Movement ABC-2]. Zeitschrift für Psychiatrie, Psychologie und Psychotherapie, 58, 227-233.

Kastner, J., Petermann, F., \& Petermann, U. (2010). Motorische Leistungsfähigkeit adipöser Kinder und Jugendlicher [Motor skills in obese children and adolescents]. Monatsschrift Kinderheilkunde, 158, 449-454.

Kerlinger, F. N., \& Lee, H. B. (2000). Foundations of behavioral research (4th ed.). Orlando: Harcourt College Publishers.

Kromeyer-Hauschild, K., Dortschy, R., Stolzenberg, H., Neuhauser, H., \& Rosario, A. S. (2010). Nationally representative waist circumference percentiles in German adolescents aged 11.0-18.0 years. International Journal of Pediatric Obesity (Epub ahead of print).

Mickle, K. J., Munro, B. J., \& Steele, J. R. (2011). Gender and age affect balance performance in primary school-aged children. Journal of Science and Medicine in Sport, 14(3), 243-248.

Mond, J. M., Stich, H., Hay, P. J., Kraemer, A., \& Baune, B. T. (2007). Associations between obesity and developmental functioning in pre-school children: A population-based study. International Journal of Obesity, 31, 1068-1073. 
Osika, W., \& Montgomery, S. M. (2008). Physical control and coordination in childhood and adult obesity: Longitudinal Birth Cohort Study. British Medical Journal, 337, a699.

Petermann, F. (Ed.). (2009). Movement Assessment Battery For Children-2 (Movement ABC-2) (2nd ext. ed.). Frankfurt: Pearson Assessment.

Polatajko, H. J., \& Cantin, N. (2005). Developmental coordination disorder (Dyspraxia): An overview of the state of the art. Seminars in Pediatric Neurology, 12, 250258.

Rivilis, I., Hay, J., Cairney, J., Klentrou, P., Liu, J., \& Faught, B. E. (2011). Physical activity and fitness in children with developmental coordination disorder: A systematic review. Research in Developmental Disabilities., 32, 894-910.

Schelbert, K. B. (2009). Comorbidities of obesity. Primary Care: Clinics in Office and Practice, 36, 271-285.

Shultz, S. P., Deforche, B., Byrne, N. M., \& Hills, A. P. (2011). Fitness and fatness in childhood obesity: Implications for physical activity. In D. Bagchi (Ed.), Global perspectives on childhood obesity: Current status, consequences and prevention (pp. 371-381). San Diego, CA: Academic Press.

Tsiotra, G. D., Flouris, A. D., Koutedakis, Y., Faught, B. E., Nevill, A. M., Lane, A. M., et al. (2006). A comparison of developmental coordination disorder prevalence rates in Canadian and Greek children. Journal of Adolescent Health, 39, 125-127.

Venetsanou, F., Kambas, A., Ellinoudis, T., Fatouros, I., Giannakidou, D., \& Kourtessis, T. (2011). Can the Movement Assessment Battery for Children-Test be the "gold standard" for the motor assessment of children with developmental coordination disorder? Research in Developmental Disabilities, 32, 1-10.

Visser, J. (2003). Developmental coordination disorder: A review of research on subtypes and co-morbidities. Human Movement Science, $22,479-493$.

Wagner, M. O., Kastner, J., Petermann, F., \& Bös, K. (2011). Factorial validity of the Movement Assessment Battery for Children-2 (age band 2). Research in Developmental Disabilities, 32, 674-680.

Wagner, M., Worth, A., Schlenker, L., \& Bös, K. (2010). Motorische Leistungsfähigkeit im Kindes- und Jugendalter-Ausgewählte Ergebnisse des Motorik-Moduls (MoMo-Studie) [Motor fitness in childhood and adolescence. Selected results from the "Motorik-Modul" (MoMo study)]. Monatsschrift Kinderheilkunde, 158, 432-440.

Willett, K., Jiang, J., Lenart, E., Spiegelman, D., \& Willett, W. (2006). Comparison of bioelectrical impedance and BMI in predicting obesity-related medical conditions. Obesity, 14, 480-490.

World Health Organisation. (1993). The ICD-10 Classification of Mental and Behavioural Disorders. Diagnostic criteria for research. Geneva: World Health Organisation.

World Health Organisation. (2007). The challenge of obesity in the WHO European region. Retrieved from http://www.euro.who.int/_data/assets/pdf_file/0008/ 98243/E89858.pdf.

World Health Organisation. (2011). Overweight and obesity. Retrieved from http://www.who.int/mediacentre/factsheets/fs311/en/.

Wrotniak, B. H., Epstein, L. H., Dorn, J. M., Jones, K. E., \& Kondilis, V. A. (2006). The relationship between motor proficiency and physical activity in children. Pediatrics, 118, e1758-e1765.

Zhu, Y.-C., Wu, S. K., \& Cairney, J. (2011). Obesity and motor coordination ability in Taiwanese children with and without developmental coordination disorder. Research in Developmental Disabilities, 32, 801-807. 